\title{
Corpus-Based Study of Discursive Representation of 'Other' in Diachronic Perspective
}

\author{
Larisa Kochetova*, and Anastasya Plavina \\ Philological Sciences, English Philology Department, Volgograd State University, Russia
}

\begin{abstract}
Based on the corpus methodology the paper presents the results of diachronic analysis of the discursive representation of 'Other' by comparing two corpora, one comprising texts of travelogues dating back to the end of the $19^{\text {th }}$ century and the corpus of present day blogs on travel. The key word tool of LancBox64 software allowed extracting the list of key words, from which lexemes that represent 'Other' were selected and categorized. The sketch tool was used to build word sketches for the lexemes identified to revel deffereces in patterns of meaning. The data obtained allowed us to contrast and compare the means of discursive representation of 'Other' in diachronic perspective, describe discursive strategies and determine historical and cultural patterns reflected in the discourse practice. Comparative analysis of statistical data in the periods under study revealed dynamic changes that are manifested in the use of peculiar nominative means that represent categories of social actors; employment of attributive and verbal evaluative lexemes that are used for discursive construing of other cultural society representatives in the consciousness of Western people.
\end{abstract}

\section{Introduction}

Discourse as speech activity occurring in the specific historical context and reflecting societial needs, beliefs and values has lately been considered in diachronic perspective, which allows one to reveal the complex and historically variable nature of human communication. Modeling of discourse in historical perspective that focuses on the discourse evolution that reveals itself in diachronic tendencies, reflecting historical variability of language structures represented in discursive forms, is considered to be an advancement in discourse studies [15]. However, historical discourse analysis seeks to investigate changes in discursive practices not only in social-pragmatic perspective, but also in relation to changes in knowledge formats and styles of thinking. This implies the research of diachronic transformation in representation of cognitive mechanisms employed by people, who are involved in social interaction, in discursive practices. To date, within the cognitive-anddiscursive paradigm the concepts of cognitive and language representation are used in different ways. Mental representation, which includes concepts, propositions, frames, scripts, scenarios, is understood as the process of displaying (representation) of the world in person's consciousness and as the unit of such representation, standing instead of something in a real or imagined world and, therefore, substituting this something in the mind of an individual person [6]. The first to point out the difference between cognitive and discursive representation of reality were Teun A. van
Dijk and Walter Kinch, who pointed out that discursive representation may not only substitute objects and actions, but also generate them as if "constructing" objects or whole situations: in other words, representations can create fictional objects, which "as though are being reflected" by these representations [7]. Theoretical grounds of discursive constuction of reality are given by S. N. Plotnikova, who is engaged with analysis of cognitive scenarios of day-to-day and other possible realities construction. S. N. Plotnikova distinguishes two types of discursive representation: 1) 'reflection/monitoring' which is a discursive representation of reality caught by author as a complete piece, as the world-without-me; 2) 'construction' which is discursive representation of reality being created and shaped by the speaker/writer. The cognitive scenario in the first representation type has a reflective nature - it is an isomorphic mental representation of events, taking place in the world being observed, which is the result of categorization. The scenario underlying in the process of reality construction is operational, as the world is being constructed here and now with the help of actions and discourse itself [8] and reflects the author's interpretation results.

In this regard, the research of discursive representation means in genres that evolve in historically different sociocultural context, aimed at identifying the reality categorization and interpretation specificity that is the result of socially determined human mental activity. Comprehending the concept of genre as a "form of cognition and conceptualization of reality" [9], we may

* Corresponding author: kochetova@ volsu.ru 
define this communication form as a cognitive model, consisting of a set of mental frames, which comprises the knowledge about the specific part of reality (see e.g. $[10]$ ) and forms the conceptual ground of the genre as a result of cognitive and semantic activity of human consciousness while categorizing and interpreting the out-world.

Each historical period in the development of communication forms is associated with a certain set of genres [11], which reflects not only the discursive practice specificity, but also differs in how the real world is shaped, categorized and interpreted in the sociocultural context of genre's functioning. Since ancient times travels and expeditions aimed at discovery of new routes, as a rule, came along with written recording of not only definite geographical and ethnographic realia, but also the reality at large. Travelogue as a genre starts to take shape round 484 BC in the travel notes by Herodotus. Such records appear to be the best material for the study of foreign reality categorization and evaluative interpretation specificity, based on pattering of personal experience in accordance with the societal and individual system of norms, ideals, stereotypes, values. This work is aimed to study diachronic changes in means of other cultural reality representation, in particular of the category of 'Other' in the travelogue and travel blog genres. Historical changes in discursive representation of reality are determined by the dynamics of knowledge structures and formats, underlying discursive practice.

\section{Methods and research material}

This investigation is based on the corpus methodology [13-17], which to date is applicable not only to synchronic language study [18-21] but also extends to diachronic analysis of changes at different language levels, as a rule, lexical, grammatical and syntactic as well as to the research of historical variability of genres, registers, regional language variants (see [22], [23]). Corpus-based diachronic approach to the language material analysis implies using comparable corpora of texts and statistical methods used in corpus linguistics. This gives the opportunity of revealing the specifics of language functioning in various historical periods basing on language system of certain time period reconstruction and the review of semantic, grammar, syntactic, stylistic and rhetoric changes. We are investigating the dynamics of diachronic changes in the English travelogue genre from late $19^{\text {th }}$ century to the present time in terms of cognitive linguistics. The research objective is revealing the cognitive and discursive patterns of reality reflection by direct observers, basing on comparative analysis of text corpora relating to two noted periods. The diachronic corpus involves texts of the late $19^{\text {th }}$ and early $20^{\text {th }}$ centuries: travel notes by British travel writers Isabella Bird (1831-1904), Mary Kingsley (1862-1900), and Gertrude Bell (1868-1926). The corpus size is 0.4 million words. At material selection for the late $19^{\text {th }}$ and early $20^{\text {th }}$ centuries we are primarily guided by the informative features of the works, namely the presence of documentary narration in texts with no pronounced storyline - the plot follows the author's route. All the works are presented in the form of diary notes or letters, what allows one to track the emergence of the genre's conceptual grounds in diachronic perspective through corpora-based analysis of reality representation or construction means. All the selected works are dedicated to the exotic for Europeans locations - Japan, Iran, Syria Lebanon, West African countries, what determines the particular interest to the cognitive description of a culture related to the native English speaker's destination. In modern communication, travel blog as an Internet genre is considered to be a form of the travelogue genre development. We have analyzed the texts of this genre within the Core Corpus of Web Registers of Brigham Young University, created by Mark Davis [12]. The travel-blogs subcorpus size is 0.3 million words. This corpus is considered to be representative for the modern British variant of language in web genres, what determined its choice as the empirical base of our research. Travel blog unlike travelogues written by British writers is an Internet user's narration about a journey or a trip mainly for the purpose of recreation and new impressions, not another culture exploration and conveying knowledge about it to contemporaries. The statistical data have been extracted from LancBox64 software, allowing one to fulfill all standard procedures of corpora-based analysis.

\section{Results of Comparative Diachronic Analysis}

We reveal the specificity of discursive representation of 'Other' that is based on the analysis of reality categorization and interpretation means employed in the genres under consideration. Comparative diachronic analysis of the genre discursive representation in the periods under study allowed us to define its universal and specific characteristics as for means used to construe reality and identify the dominant discursive representation strategy. In order to describe the representation of 'Other' through corpus-based research and reveal the diachronic specificity of categorization and evaluative interpretation in the texts, the main representative lexical means have been selected with further analysis of their frequencies in the periods compared. We categorized the lexemes, representing 'Other', basing on the theory of social actors, developed by $T$. van Leeuwen, who distinguished three types of categorization: functionalization, identification and evaluation. Functional criterion allows one to refer to the same category lexical means that denote people's profession; identification implies lexical means, describing relatively constant features of an object [24]. Functionalization falls into three subcategories: classification, including sociodemographic features such as age, sex, ethnicity, nationality, confession, etc.; relative identification, comprising various social roles and relationship types between people, and physical identification, implying appearance, clothes, skin colour, 
etc. Evaluative category is represented with evaluative and affective vocabulary. Then, we fulfilled the contextual analysis of the tokens, selected that allowed us to describe the historical specifics of reflective and interpretative activity of travelogue authors. Data on frequency of units that are used to nominate residents as members of a different cultural community, are presented in Table I.

Table 1. Lexical means of discursive representation of 'Other' with indication of Absolute and Relative frequencies (per $10^{\text {th }}$ words in diachronic corpus.

\begin{tabular}{|c|c|c|c|c|c|}
\hline \multirow{2}{*}{ Category } & \multirow{2}{*}{ Token } & \multicolumn{2}{|c|}{ 19th century } & \multicolumn{2}{|c|}{ 20th century } \\
\hline & & \begin{tabular}{|l} 
Relative \\
frequency
\end{tabular} & $\begin{array}{l}\text { Absolute } \\
\text { frequency }\end{array}$ & $\begin{array}{l}\text { Relative } \\
\text { frequency }\end{array}$ & $\begin{array}{l}\text { Absolute } \\
\text { frequency }\end{array}$ \\
\hline \multirow{12}{*}{$\begin{array}{l}\text { General } \\
\text { terms }\end{array}$} & people & 12.58 & 559 & 214.42 & 709 \\
\hline & locals & 0.00 & 0.00 & 2.99 & 99 \\
\hline & groups & 0.92 & 41 & 1.84 & 61 \\
\hline & team & 0.00 & 0 & 1.51 & 50 \\
\hline & crowd & 1.73 & 77 & 0.85 & 28 \\
\hline & crowds & 0.41 & 18 & 0.60 & 20 \\
\hline & population & 1.10 & 49 & 0.57 & 19 \\
\hline & individuals & 0.69 & 31 & 0.51 & 17 \\
\hline & tribe & 6.03 & 268 & 0.36 & 12 \\
\hline & savages & 2.30 & 102 & 0.00 & 0 \\
\hline & slave & 1.68 & 75 & 0.00 & 0 \\
\hline & savage & 1.37 & 61 & 0.00 & 0 \\
\hline \multirow[t]{3}{*}{ Provenance } & residents & 0 & 0 & 0.73 & 24 \\
\hline & \begin{tabular}{|l} 
native \\
\end{tabular} & 4.41 & 196 & 0.54 & 18 \\
\hline & inhabitant & 1.48 & 66 & 1.21 & 4 \\
\hline \multirow[t]{10}{*}{ Nationality } & Cuban & 0 & 0 & 0.69 & 23 \\
\hline & Japanese & 1.01 & 45.00 & 0.00 & 0 \\
\hline & Turks & 0.83 & 37.00 & 0.00 & 0 \\
\hline & Arab & 1.48 & 66 & 0.00 & 0 \\
\hline & Arabs & 0.65 & 29 & 0.00 & 0 \\
\hline & Aino & 2.43 & 108 & 0.00 & 0 \\
\hline & Ainos & 2.20 & 98 & 0.00 & 0 \\
\hline & negro & 1.21 & 54 & 0.00 & 0 \\
\hline & Bantu & 0.72 & 32 & 0.00 & 0 \\
\hline & $\begin{array}{l}\text { Vietnames } \\
\mathrm{e}\end{array}$ & 0.00 & 0 & 0.39 & 13 \\
\hline \multirow[t]{12}{*}{ Occupation } & \begin{tabular}{|l|} 
servant \\
\end{tabular} & 1.35 & 60 & 0.00 & 0 \\
\hline & farmer & 0.29 & 13 & 1.51 & 5 \\
\hline & guide & 0.54 & 24 & 3.26 & 108 \\
\hline & driver & 0.00 & 0 & 1.40 & 46 \\
\hline & artists & 0.00 & 0 & 0.81 & 27 \\
\hline & guides & 0.00 & 0 & 0.78 & 26 \\
\hline & drivers & 0.00 & 0 & 0.32 & 17 \\
\hline & witch & 0.87 & 39 & 0.00 & 0 \\
\hline & owner & 0.00 & 0 & 1.18 & 39 \\
\hline & interpreter & 0.60 & 27 & 0.00 & 0 \\
\hline & merchant & 0.42 & 19 & 0 & 0 \\
\hline & peasant & 0.42 & 19 & 0 & 0 \\
\hline
\end{tabular}

As the data given in Table 1 show, the most frequent word, nominating representative of another culture in the $19^{\text {th }}$ century corpus is the noun tribe, with the meaning 'a large group of related families who live in the same area and share a common language, religion, and customs' and represents the residents of destination countries not as individuals but as an exotic homogeneous group. The frequency of a collective noun people in the $19^{\text {th }}$ century is comparable to its frequency in the $20^{\text {th }}$ century corpus; in the $19^{\text {th }}$ century corpus local people are nominated with pejorative words, such as savage(s), slave. This discursive practice indicates high social status of the author. In the $19^{\text {th }}$ century corpus the lexical units nominating nationalities are dominant in comparison to the $20^{\text {th }}$ century corpus: Japanese, Arabs, Turks, whereas in modern travel blogs this vocabulary is rather rare, e.g. Vietnamese, Cuban. In the $20^{\text {th }}$ century collective nouns crowd, people are not often used, and the noun locals is characterized by the highest frequency. This difference accounts for distinguishing the local people and tourists by travel-blogs authors. In the $19^{\text {th }}$ century corpus the lexical means denoting the occupation of locals that usually refer to the idea of low social status, e.g. servant, farmer, peasant, are rather rare. In the $20^{\text {th }}$ century we observe high variability of nomination in this category and selected means of nomination demonstrate that local people are mostly engaged in service sphere. In the $19^{\text {th }}$ century corpus discursive representation of local people involve description of appearance, manners, behavior, character features and clothes. In the $19^{\text {th }}$ century texts, evaluative description of local people is ambivalent, and they are characterized as kind, quiet, polite, hospitable and hardworking: The people are so quiet and kindly, though almost too still; on the other hand, the image of Asian people in the Western mind implies inner and outer deficiency, scarce intelligence and ugly appearance. In discursive construction of a strange reality appearance of local people receives negative evaluative categorization and they are characterized as ugly, e.g.: the oldest little ugly pathetic face, ugly Japanese face, ugly, kindly-looking face; unusual face features, e.g. face colour (yellow face) are emphasized.

Local people are compared to savages, i.e. the representative of primitive peoples: Their houses were dirty, and, as they squatted on their heels, or lay face downwards, they looked little better than savages. Their appearance and the want of delicacy of their habits are simply abominable, and in the latter respect they contrast to great disadvantage with several savage peoples that I have been among. <..> They are courteous, kindly, industrious, and free from gross crimes; but, from the conversations that I have had with Japanese, and from much that I see, I judge that their standard of foundational morality is very low, and that life is neither truthful nor pure.

In the given example despite the acknowledgement of positive features of local people, described by the author as polite, kind, hardworking and not prone to committing crimes, the negative evaluation of their homes (dirty), behavior and manner (abominable) is transferred to their moral character, identified as not pure. This fragment sustains the view of V.I. Karasik, who points out that in English society cultural-genetic conceptualization of dirt as "something not clean" defines the high sensitivity of society members to purity and filth that are realized as a form of legitimacy and illegitimacy of behavior and its means [10]. Context 
analysis shows the lack of individualization in discursive representation of locals in the $19^{\text {th }} \mathrm{c}$. and they are represented as a homogeneous group, not diverse in age, social status or sex, e.g.:

The villages of that district must, I think, have reached the lowest abyss of filthiness in Hozawa and Saikaiyama. Fowls, dogs, horses, and people herded together in sheds black with wood smoke, and manure heaps drained into the wells.

In the course of discursive representation, 'Other' is perceived as something ridiculous: It is most comical to see stout, florid, solid-looking merchants, missionaries, male and female, fashionably - dressed ladies, armed with card cases, Chinese compradores, and Japanese peasant men and women flying along Main Street, which is like the decent respectable High Street of a dozen forgotten country towns in England, in happy unconsciousness of the ludicrousness of their appearance; racing, chasing, crossing each other.

The verbs flying, racing, chasing, crossing possess pejorative semantics of chaotic movement, which is typical for insects or animals, are used in discursive representation of 'others', which contrasts with the bright looks of the depicted inhabitants. The adjective comical and the noun ludicrousness represent author's evaluative construction of reality that is characterized as comic, ridiculous and provoking laughter.

We have compared the context around the most frequent noun in the diachronic corpora - people, presented with adjectives of mostly evaluative semantics.

The descriptions of locals, produced by travel blog authors of $20^{\text {th }}$ century emphasize the hospitality, cordiality, goodwill towards foreigners, e.g.: A little bloke called Mohammed broke my heart. He's 14 and his face is lit up by huge white teeth and an unfailing impish grin. It was his grin that struck me and it's that smiling, welcoming face that's dead-set haunting me right now. They did everything to make us feel welcome. The other locals we encountered extended similar hospitality. In the given example the smile on a face of the local boy which signals about desire to serve is accented.

In the abstract above, the author emphasizes a smile on the face of a local boy, which indicates the desire to serve. Discursive representation of local people is often reduced to the accentuation of particular appearance features: I went to go back in, but a burly Indian man with a big mustache (I don't think it was for Movember) and a gun told me I couldn't go back in with my luggage. The other noticeable thing is the array of very different looking Cubans. Their skin colour comes in about 14 different shades. From very dark carribbean to very light almost white and everything in between.

In the next text fragment the blog author construes the typical image of a local guide - a young man always ready to help and provide the necessary information: $W e$ have had three local guides in Vietnam, one in Hanoi, one in Saigon, and one on the Mekong River up to the Cambodian border. Each was a young man, eager to be informative and helpful. Hard to generalize from a very few individuals, but the Hanoi guide seems a bit more formal and reticent, both proud and a little prudish. The two in the south were more outgoing and seemed more familiar and western in both dress and manner.

Due the given example we conclude that Western mind associates such behavior peculiarities as restraint and pride with the representative of Asian peoples, while the western cultures representatives are regarded to be more open and outgoing. In Table 2 we provide data on frequency of the attributes that precede the noun people.

Table 2. Attributes of the noun 'people' in diachronic corpus with indication of Absolute and Relative frequencies (per $10^{\text {th }}$ words in diachronic corpus.

\begin{tabular}{|l|c|c|c|c|}
\hline \multirow{2}{*}{ Token } & \multicolumn{2}{|c|}{ 19th century } & \multicolumn{2}{c|}{ 20th century } \\
\cline { 2 - 5 } & $\begin{array}{c}\text { Relative } \\
\text { frequency }\end{array}$ & $\begin{array}{c}\text { Absolut } \\
\text { e frequency }\end{array}$ & $\begin{array}{c}\text { Relative } \\
\text { frequency } \\
\text { ute } \\
\text { frequency }\end{array}$ \\
\hline friendly & 0.61 & 27 & friendly & 0.05 \\
\hline tribal & 0.52 & 23 & young & 0.03 \\
\hline local & 0.45 & 20 & local & 0.03 \\
\hline ugly & 0.43 & 19 & great & 0.02 \\
\hline kindly & 0.29 & 13 & curious & 0.01 \\
\hline quiet & 0.22 & 10 & proud & 0.01 \\
\hline industrious & 0.22 & 10 & wonderful & 0.01 \\
\hline courteous & 0.20 & 9 & lovely & 0.01 \\
\hline polite & 0.12 & 6 & Chinese & 0.01 \\
\hline stupid & 0.10 & 5 & Vietnamese & 0.01 \\
\hline friendly & 0.61 & 27 & friendly & 0.05 \\
\hline tribal & 0.52 & 23 & young & 0.03 \\
\hline
\end{tabular}

\section{Conclusion}

The analysis of two diachronic corpora allowed us to reveal the representation specificity of 'Other', which reflects the results of cognitive and interpretative activity of discourse subjects, as well as the dynamics of categorization and interpretation of 'Other' in different time periods.

The analysis of lexical means used to nominate local people as the most prominent element of discursive representation together with the analysis of their frequencies allowed us to conclude that the most frequent noun in the $19^{\text {th }}$ century is people, whereas in the $20^{\text {th }}$ century the noun locals is dominant. This demonstrates the tendency to distinguish local people and tourists in a contemporary genre of Internet travel blog. Differences in patterns of meaning between two corpora are reflected in the use of pejorative nominations of local people in the $19^{\text {th }}$ century that indicates high social status of the discourse author. More frequent nominations of nationalities in comparison to the $20^{\text {th }}$ century corpus is due to the higher interest in exotic nations and more emphasized attitude to them in the $19^{\text {th }}$ c. Analysis of discursive representation of occupations shows that in both corpora occupations of local people are usually associated with low social status.

In general, the analysis has shown that the basis of local people discursive representation in the genre of travelogue of the $19^{\text {th }}$ century is the interpretation that construes the representatives of foreign culture as a homogeneous group that possesses some generalized 
features. The reflective scenario accentuates certain aspects of appearance and behavior, which significantly deviate from the norms existing in the author's culture, and often receive pejorative characterization. This scenario implements the discursive strategy of alienation.

In the $20^{\text {th }}$ century corpus, the reflective scenario accentuates the distinctive individual characteristics of the local people appearance. Evaluative interpretation by the discourse subject is not pejorative. Moreover, local people are placed in the focus of empathy.

Further contextual analysis of the revealed lexical units will allow one to clarify the differences in the evaluative categorization in the English travelogue genre in various historical periods, and the data generalization for different periods will highlight the dynamics in the strategies of foreign culture discursive representation and reveal historical and cultural patterns of their realization in English tradition of publicist discourse.

\section{References}

1. L.J. Brinton, The Handbook of Discourse Analysis (Oxford, Blackwell, 2001), 138-160.

2. R. Carroll, J. Skaffari, The European English Messenger 11 (2), 48-52 (2002)

3. J. Culpeper, Journal of Historical Pragmatics 10 (2), 179-186 (2009).

4. A.H. Jucker, English Diachronic Pragmatics. (Napoli: CUEN, 2000), 17-55.

5. E.Yu. Ilyinova, L.A. Kochetova, Science Journal of VolSU. Linguistics 15 (4), 18-25 (2016).

6. E.S. Kubrjakova, Jazyk $i$ znanie, (Moscow, Jazyki slavjanskoj kul'tury 2004).

7. E.S. Kubrjakova, V.Z. Dem'jankov,Voprosy kognitivnoj lingvistiki 4, 8-16 (2007).

8. S. N. Plotnikova, Izvestija of Volgograd State Pedagogical University, Volgograd 5 (90), 41-46 (2014).

9. C.A. Newsom, Emory University, Atlanta 17, 270288 (2010)

10. N.N. Boldyrev, Kognitivnye issledovanija jazyka 3, p25-77 (2009).

11. V. I. Karasik, Jazykovoj krug (Gnozis, Moscow, 2002).

12. D. Biber, J. Egbert, M. Davis, Corpora 10 (1), 1145 (2015).

13. N. C. Ellis, Studies in Second Language Acquisition 24 (2), 143-188 (2002).

14. G. Th. Gilquin, Corpus Linguistics and Linguistic Theory 5 (1), 1-26 (2009).

15. G. N. Leech, Proceedings of Nobel Symposium 82, (Mouton de Gruyter, 1992)

16. T. McEnery, A. Wilson, Corpus Linguistics, (University Press, Edinburgh, 2001).
17. T. McEnery, A. Hardy, Linguistics: Method, Theory and Practice (Cambridge University Press, Cambridge, 2011).

18. J. Laws, C. Ryder, IJCL 23 (1), 1-27 (2018).

19. D. Biber, B. Gray. Grammaical Complexity in Academic English (Cambridge, 2016).

20. P. Crompton, Corpora 12 (1), 1-27 (2017)

21. L.A. Kochetova, E.Yu. Iilyinova, Analele Universităţii Ovidius din Constanţa. Seria Filologie 1, 85-98 (2017).

22. Diachronic Corpora, Genre, and Language Change. Conference, University of Nottingham, 2016. https://www.nottingham.ac.uk/conference/facarts/clas/dcglc/home.aspx

23. V.D Solov'ev, Russian Language: functioning and evolution (Kazan, 2012)

24. T.van Leeuwen, Texts and Practices: Readings in Critical Discourse Analysis (Routledge, London, 2003) 